\title{
The changing faces of the concrete balustrade in Nigerian vernacular architecture
}

\author{
C. O. Osasona \& F. O. Ewemade \\ Department of Architecture, Obafemi Awolowo University, Nigeria
}

\begin{abstract}
A balustrade is an architectural contrivance used to delimit space, as an aesthetic complement, to provide protection, or for a combination of these functions. It is associated mainly with bridges, balconies and staircases. In the context of balconies and verandas, it is more a feature of tropical and the Mediterranean, rather than temperate climates. In Nigeria, the balustrade dates back to colonial and colonially-facilitated architecture. It has been observed that, with the entrenchment of vernacular practices, rather than dim in prominence (with the fading away of the ornate Brazilian style) it is progressively being re-crafted and re-contextualized - demonstrating its wide acceptance and versatility. While materials such as glass and wrought-iron feature prominently in modern expressions, in the light of the ongoing romance with re-visiting pseudoClassical orders in contemporary architecture in the country, the concrete balustrade appears to have come into its own again. Contemporary practice favours the baluster-type balustrade. Traditional motifs included stylized floral, geometric or abstract, and even featured customizing calligraphy. Traditional production methods and implements were basic, and the output somewhat crude. Contemporary-type balustrades could be factory-produced (hence, standardized and exhibiting greater finesse) or also casually produced. This paper focuses on the transformations that have taken place in formal expressions of the concrete balustrade in Nigeria, using the southwest as a case-study. It traces the origins of the concrete balustrade in Nigeria (observing the motifs and crafting techniques) and in the light of various predisposing factors (such as wide social acceptability and economic sustainability) and identifies the current revival of the craft as a possible defining phenomenon underpinning architecture-based tourism in the country.
\end{abstract}


Keywords: baluster, balustrade, Nigerian vernacular architecture, AfroBrazilian, Brazilian architecture, wooden dummy, quarry dust, mould, plasterof-Paris, stylistic revival.

\section{Introduction}

Pre-fabrication, a major facilitator of much of post-World War re-construction efforts in Europe, has been taken to heights that could not have been anticipated at the turn of the Twentieth Century: with the exploits of Productivism [1], virtually every element of a building can now be expressed as a triumph of the factory process. Locally in Nigeria, the integration of pre-fabricated elements into the building process is still in relative infancy. Apart from large consortia and other long-established companies of repute handling multi-million dollar commissions, much of the building culture still has recourse to conventional in-situ site development practices as well as the routine use of basic premoulded-and-dried building units.

The general limited use of pre-fabrication notwithstanding, even in domestic residential Nigerian architecture, it is possible to observe a trend that is gradually gaining ground, whereby certain areas of a building are becoming favoured for incorporating other-than-routine pre-fabricated elements. This has largely been aided by the wave of architectural eclecticism and general quasi-historicism that appears to be sweeping across the nation. This phenomenon is characterized by a re-calling of features from the Classical period of architectural history, and reinterpreting them in contemporary Nigerian architectural contexts of design form, material and technique. Specifically, on the local scene, popular architectural features in historical re-evolution include columns, pediments, quoins, cornices, arches, dadoes and balustrades. A balustrade is defined as "a row of upright posts or small pillars joined at the top by concrete rails" [2]. It is a building element used mainly around a balcony, staircase and so on. Stating the obvious, the balustrade, when used in veranda and staircase areas in a multistorey building, helps to protect the users of the facility from falling over. It also serves as a decorative element in the design of building façades. If properly designed and constructed, it enhances the aesthetic perception of the facade where it is applied, and by extension, the overall composition of the structure. Pre-cast balusters have the potential to make the construction process fast (in Nigeria, they can be made and purchased readily by the roadside) - a major advantage also of other pre-fabricated building elements.

In Nigeria, the use of the balustrade (as a building expedient sporting inherent ornamentation) was a colonial innovation - as was building on more than one level. The tropicalized variant of building in the spirit of the Modern Movement featured, among other things, the use of pronounced eaves, sun-shading devices (such as fins, window hoods and verandas), terraces and light-coloured paints [3]. The balustrade was an integral part of all veranda/porch, balcony and staircase articulations. Since colonial buildings were both in timber and masonry (i.e. stone or burnt brick), balustrades were expressed either in wood or stucco. 


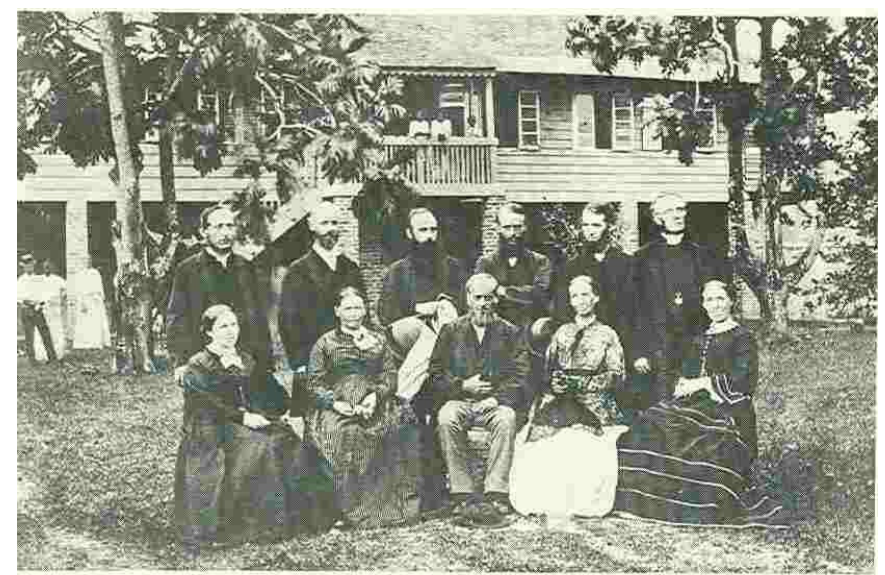

Rev. H. Townsend (seated centre) and other missionaries, 1843

Figure 1: Missionaries photographed in front of a typical colonial mission house; Lagos. Notice the wooden balusters framing the balcony [4].

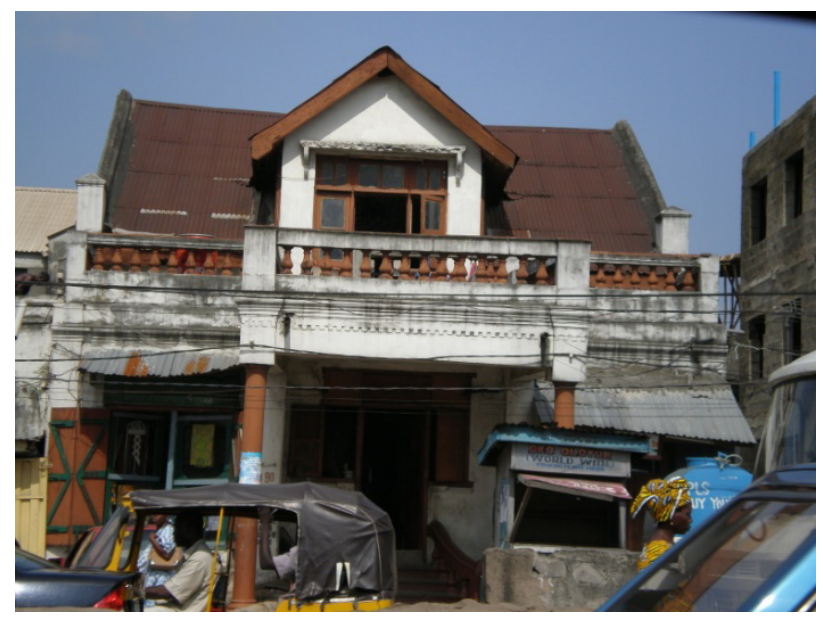

Figure 2: Second-generation Afro-Brazilian house ca. 1960; Yaba, Lagos. Squat, bulbous concrete balusters are used in the balcony.

Generally, these were simple, essentially utilitarian elements, with aesthetics not a major consideration. Fig. 1.

With the repatriation of African slaves from the Latin Americas (particularly Bahia in Brazil), the architectural scene in Nigeria became significantly impacted $[5,6]$. The role of the British (who had colonized Nigeria well ahead of this) is a well-recorded historical fact; suffice to say they facilitated the importation of the "Brazilian Style" (itself a derivative of the Portuguese style) into the country. Prior to this (and to the direct colonial influence), Nigeria had had many forms of traditional architecture. These ranged from massed-earth or skeletal structures in 


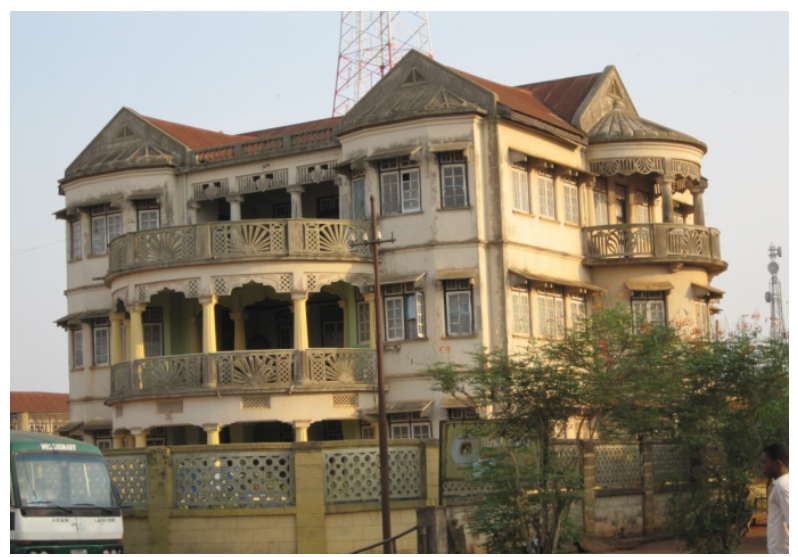

Figure 3: Kekere-Owo house, Ijebu-Ode. Built in the 1940s, it features concrete panel balustrades (and fretwork), but also has balusters at roof level.

the far north; through wattle-and-daub (and other composite arrangements) in the Middle Belt, to masonry or cane-on-stilt construction in the south [7]. Inherent in these traditional building types were ethnically-derived ornamental expressions some as "art for art's sake", and others as cultural sign-posts or general social commentary. Even though some of these traditional house-types featured verandas, these either did not call for the balustrade as a special feature (as with the Yoruba impluvium-courtyard type) or, because of limited applicability in their peculiar expression, they were not typical (e.g. the veranda of the entrance hut, katamba, of the Nupe in which balusters were only dramatic if it was the ruler's hut). However, with the advent of the Brazilian style which was famous for its Baroque-type ornateness (and characterized by multi-storey construction, balconies and the presence of the garret), various building elements became conferred with special aesthetic attention. As was to be expected, balustrades attached to staircases, balconies and verandas in such buildings became more aesthetically-endowed than previously. Figs. 3 and 4 show two Afro-Brazilian houses in Ijebu-Ode in which such balustrades featured.

\section{Concrete balustrades in Nigerian architectural history}

Essentially, buildings by colonials featured balustrades made up of individual newels. Commonly, too, when balustrades framed uncovered porches or terraces, they were of stucco; however, as veranda railings, they were more often timber, but could also be spare-framed masonry panels (see fig. 5). On the other hand, with the Brazilian/Afro-Brazilian building types, invariably all external balustrades were of masonry, while ornate wood-carving was reserved for internal staircase balustrades. Similar to Art Nouveau practices, with Brazilianstyle construction, each commission was a display of artistic creativity, and 
resulted (as far as balustrade design was concerned) in an infinite array of motifs and compositions. Figs. 7-12 are some samples from Ile-Ife.

Basically, the concrete balustrade comes in two forms: as single balusters embedded in flooring and braced together by a concrete handrail, or as a perforated slab (or panel), anchored to concrete uprights and topped by a handrail. In the light of ongoing practices vis-à-vis the incorporation of the balustrade in building design, the panel-type concrete balustrade has not just waned in popularity, but has become quite obsolete - with the exception of the earlier-mentioned skeletal-framed panel, with a criss-cross motif. This particular motif has been re-called and is being expressed these days, not in reinforced concrete, but rather in hollow metal pipes or as welded steel sections. See fig. 6 .

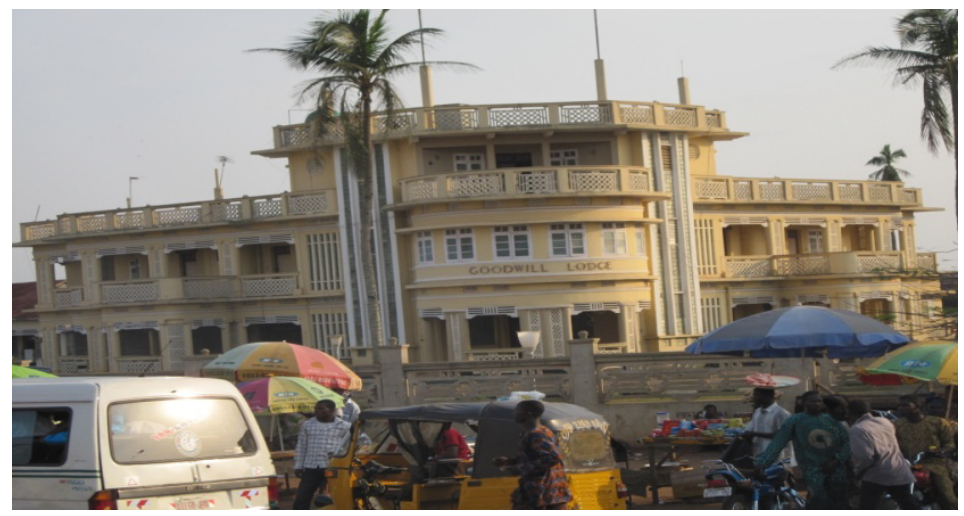

Figure 4: Goodwill Lodge (Okunnowo house), Ijebu-Ode was built in the early 1960s; it is copiously balustraded with perforated panels.

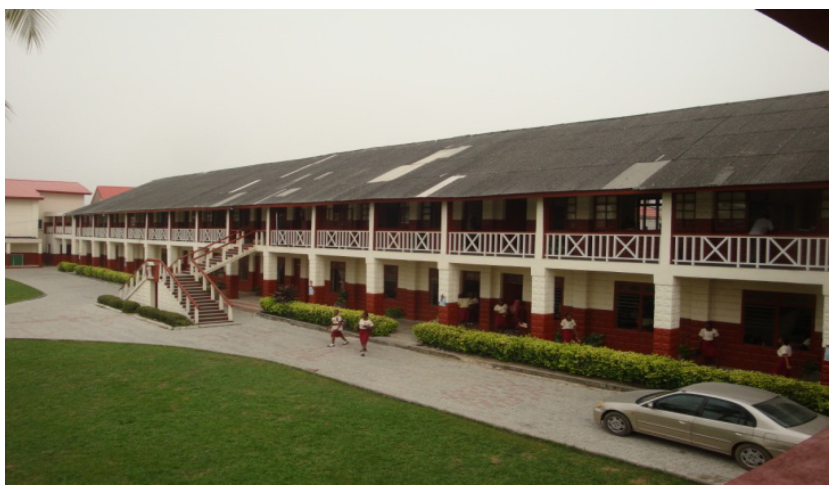

Figure 5: Holy Child College, Lagos; built in 1945. First school block. Skeletal concrete panel, with ' $\mathrm{X}$ ' motif. 


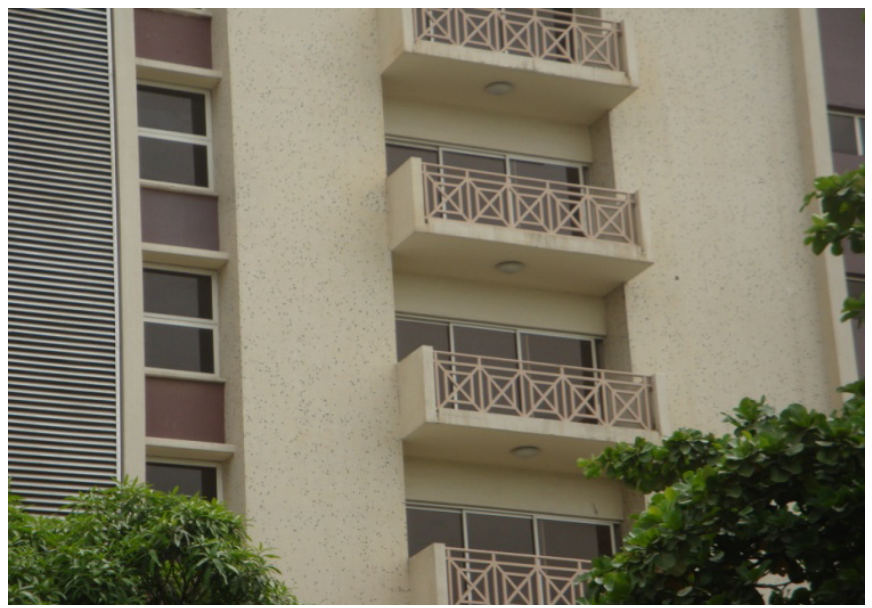

Figure 6: High-rise multi-apartment building, Ikoyi, Lagos, March, 2010; yet to be let. Balconies feature the colonial balustrade motif, adapted.

\subsection{Indigenous production of the panel-type balustrade}

Cement mortar was the major material used in the indigenous production of this balustrade. It was basically a mixture of cement, coarse sand and water to achieve a consistency that could support itself [8]. The mortar was nominallyreinforced with oja ogba (i.e. approximately $40 \mathrm{~mm}$-wide strips of flat, relatively thin, sheet metal), or $10 \mathrm{~mm}$ iron reinforcement rods. See figs. 7 and 11 . Where there were to be some perforations, areas next to such were extra-reinforced with the oja ogba, at inception. With such slightly perforated balustrades, the affected areas were cut open with a hand trowel (Fig. 11). With more complex (invariably heavily-perforated) balustrades, rod reinforcement was used. Curing was enhanced by covering the slabs with a layer of plastic or other water-proof material, and continued, with the sprinkling of water on the surface, for a period of about two weeks. The slab was then lifted off the ground and placed at the appropriate location along the balcony, between two columns. After this, the wooden formwork for the handrail was prepared, and the concrete poured. Examples of this type of balustrade are shown in figs. 7-10.

\section{Contemporary concrete balustrades}

With the advent of both colonially-inspired-and-built structures as well as the Brazilian architectural models to the Nigerian landscape, there was a progressive transference and general influencing of building styles. Initially, in the major cities of the south-west of the country (such as Lagos, Ibadan, Ijebu-Ode and Ilesa), there were near-direct transplants of the foreign models. However, over decades of selective borrowing, adaptation and integration with the extant traditional building types, a vernacular building culture evolved. A major 


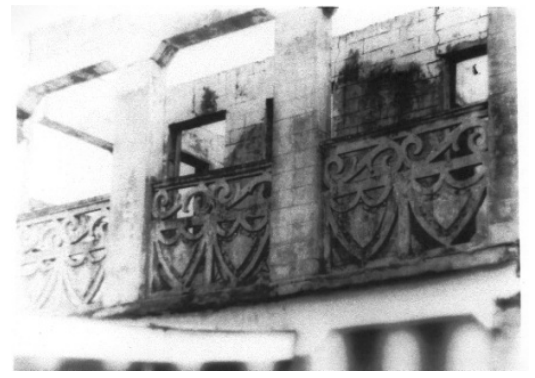

Figure 7: Battle-shield balustrade on a house razed by fire.

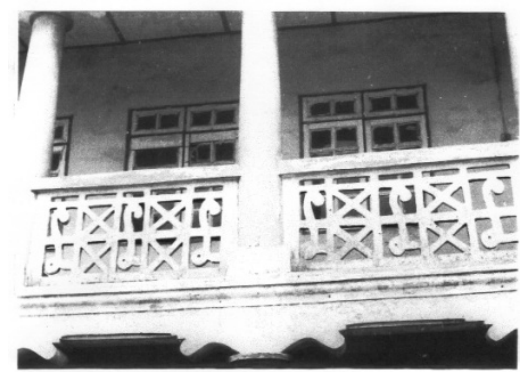

Figure 9: Motif featuring the pound sterling symbol.

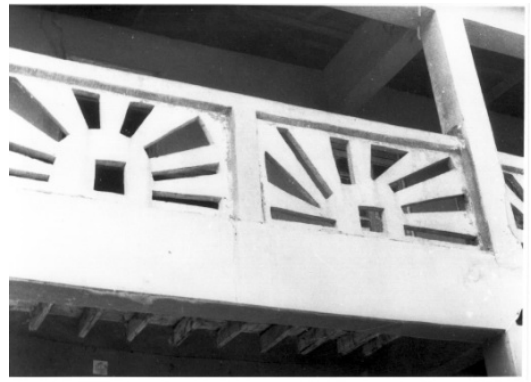

Figure 11: Panel balustrade, with scooped-out openings.



Figure 8: $\quad$ Stylised floral motif, used with geometric forms.

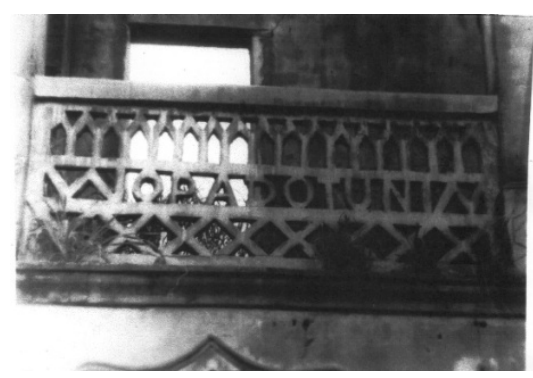

Figure 10: Customized panel with family name (Opadotun).

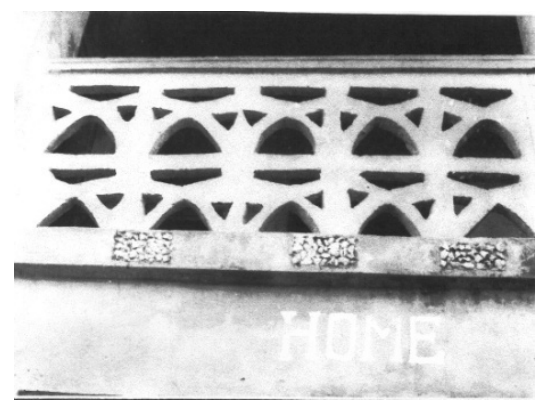

Figure 12: Heavily-perforated panel balustrade. 


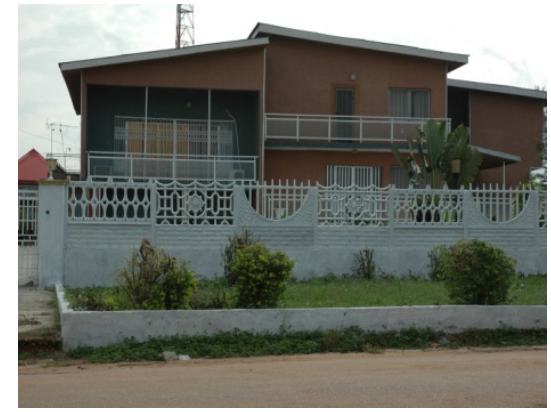

Figure 13: Balustrades in "modern" materials: glass-andaluminium balustrades, with factory-produced panels as fencing, Ondo.

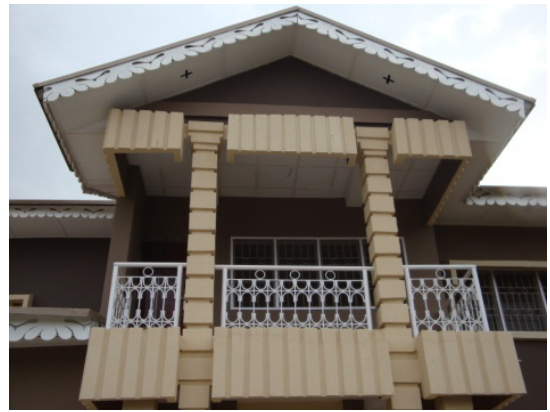

Figure 14: Balustrades in "modern" materials: metal balustrade using galvanized pipes and reinforcement iron, Ile-Ife.

characteristic of this culture was the conscious infusing of decoration to buildings. Initially, this generated a class of building closely akin to the Brazilian which, as such, was dubbed "Afro-Brazilian"; however, as the volume of ornamentation became progressively whittled down - and the general essentials of the style became increasingly popular and widespread - it is contemporarily regarded as the vernacular (or folk) architecture, nation-wide. The concrete balustrade has been a bold, long-standing feature of the country's vernacular architecture, with varying expressions of motif reflecting the nation's greatly diversified cultural dispositions. Contemporarily, it is still characteristic; undoubtedly, it is back in vogue. The most significant fact of its present existence, however, is the apparent romance with returning to the genesis of the phenomenon - an attempt, as it were, to recall the roots of the practice.

Prior to this renaissance, with the widespread influence of the International Style and the promotion of glass and steel among non-traditional building materials [9-11], balustrade design in Nigeria had undergone a revolution. There had been a widening of the design and material scope to include wrought-iron; masonry (including the use of perforated blocks), reinforced-concrete panels (solid, and merely embossed or otherwise textured); wire-reinforced or fibreglass panels in aluminium frames (i.e. composite designs) and factory-produced concrete-panel balustrades. Figs. 13 and 14 show some of the new expressions.

Despite the relatively wide array of options now available on the architectural scene, the baluster-type concrete balustrade is proving the most popular, and currently commands a large production turn-over. Quite apart from the interesting designs being evolved, a major point of interest in the phenomenon is the fact of the trend being, essentially, a revival (as it will be recalled such balustrades had been common with the early Brazilian-style - and the later AfroBrazilian derivative). Perhaps the chief factor that has facilitated this revival, has been the persistent recourse Nigerian architects have had, in the last 10-15, years to drawing formal inspiration for their designs from the colonial as well as the 
more distant Greco-Roman past - resulting in hybrid, quasi-historicist compositions - a fertile ground in which the baluster-type concrete balustrade appears to have flourished. In this variant, the balustrade is composed of individual balusters that are basically cylindrical in shape and are made primarily from quarry dust, sand and cement, with iron rods for reinforcement and fixing.

\subsection{Production of baluster-type balustrades}

A wooden version of the expected stucco baluster (i.e. a dummy), is made with a turning machine. See fig. 15. It is dressed with sand-paper, as its texture will ultimately be transferred to the cement-mortar mould. It is then carefully painted with "black oil" i.e. spent engine oil turned black from use, (to serve as a separator between the poured mortar and the dummy). A formwork of wood or sheet metal is made to house the sculpted wooden dummy, to produce a mould of stucco or gypsum (i.e. "Plaster-of-Paris", POP). The dummy is placed accurately in the centre of the formwork, ensuring a minimum all-round allowance of 50 $\mathrm{mm}$ (which will eventually constitute the thickness of the mortar or POP mould); the medium in which the mould is to be expressed is then poured into the formwork. These balusters are made using 2- or 3-piece moulds. See figures 15 and 16). Each part of the mould is reinforced by chicken wire-mesh, in order to improve its tensile strength. The mix is left for some hours to set, after which the formwork is removed to access the freshly-cast mould on which the original pattern on the wooden dummy has been transferred. Sand and stone dust are thoroughly mixed together and added to cement in the ratio of 1:5 (i.e. one part of cement to five parts of the mixture of sand and stone dust), to produce the

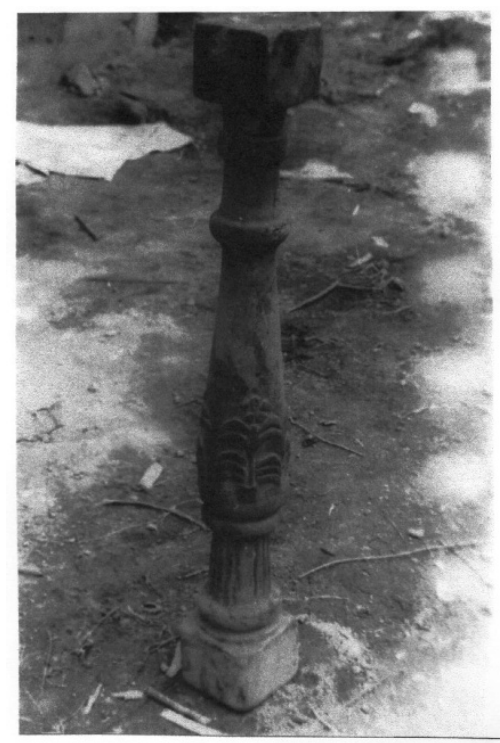

Figures 15: Wooden dummy.

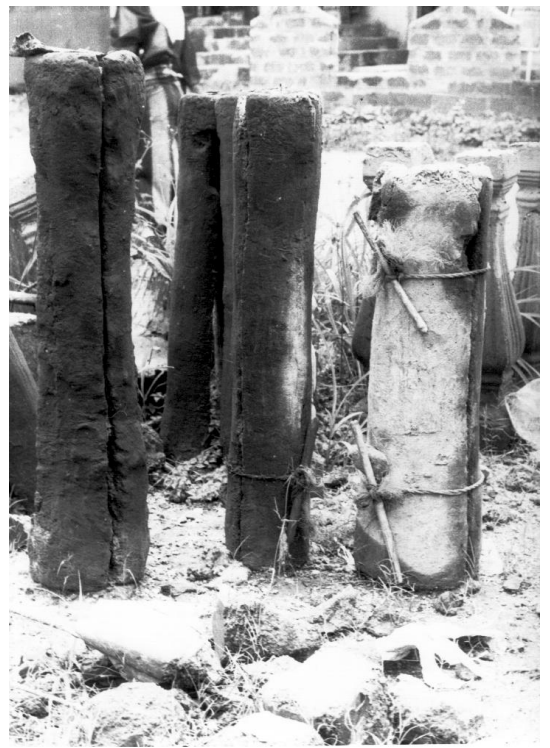

Figures 16: Balusters still in moulds. 
actual balusters; this can be varied, depending on the strength expected of the final product. The concrete mix is then poured into the mould, in the centre of which a length of $12 \mathrm{~mm}$ reinforcement rod would have been inserted. This rod will facilitate the eventual anchorage of the baluster, when it takes its place in a balustrade. Balusters are produced in various sizes, ranging commonly from 450$750 \mathrm{~mm}$ in height. Between 15 and 30 balusters can be made from a bag of $50 \mathrm{~kg}$ ordinary Portland cement - depending on bulkiness of form and height of the baluster. Figs. 17-19 show samples of such balusters and balustrades.

\section{The concrete balustrade in use}

The germaneness of a study on the baluster-type concrete balustrade centres on the employment prospects generated by its production, its potential for social-

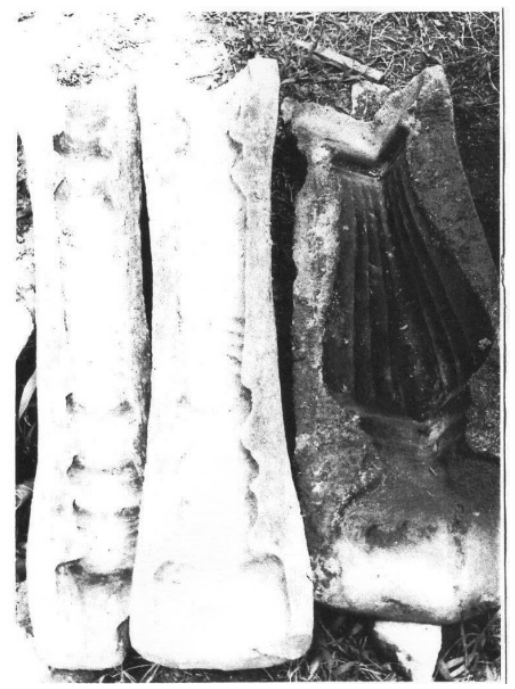

Figures 17: Two-piece moulds.

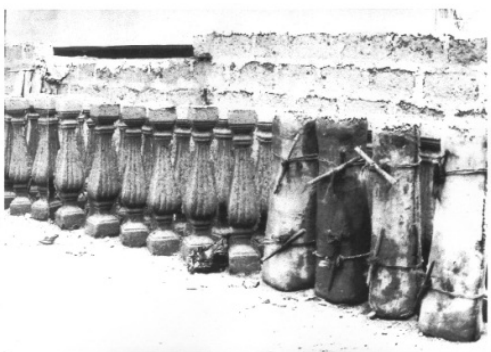

Figures 19: Bulbous balusters, exposed and some still in moulds (right).

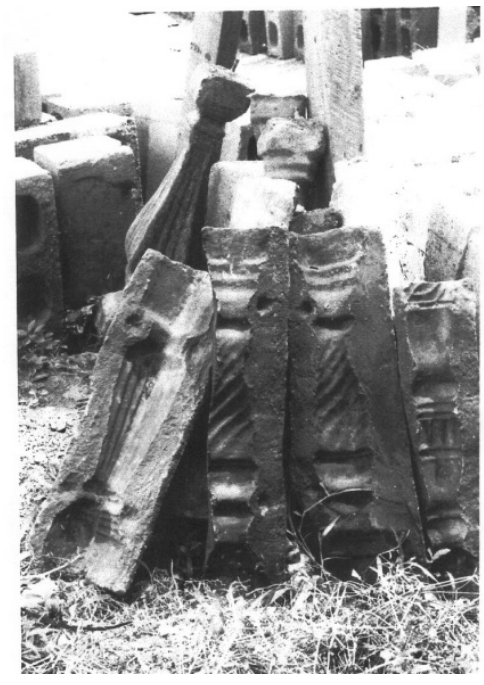

Figures 18: Three-piece moulds.

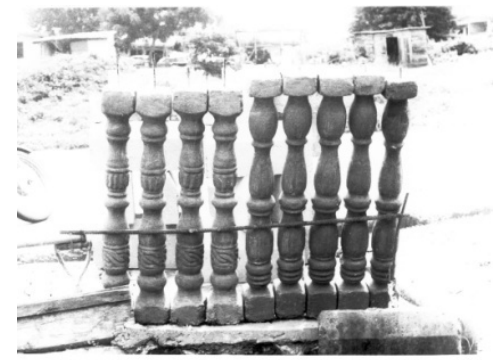

Figures 20: Slim, cylindrical balusters. 
status enhancement and its latent topicality in giving expression to ongoing design experiments in the country - among other things.

\subsection{The balustrade and socio-economic sustainability}

Baluster design and production is now very popular among building blockmakers across Nigeria. This avenue has been created by the pronounced trend in Nigeria's present building culture whereby, stately homes - in the spirit of colonial residences and Roman villas - are being proliferated all over the country. It would appear that the country's return to democratic rule has generated a social class that can afford such prestigious buildings; in addition, the economic reforms that have taken place within the last six years, created healthy rivalry among banks who have been in competition since: each has been trying to make a statement by "branded" architecture for bank premises, and sponsorship of other building projects (often expressed in the vocabulary of ornate concrete balusters currently in vogue), as part of their "social responsibility" contributions. This flurry of building activity (with a noticeable presence of the concrete balustrade) has provided job opportunities for many Nigerians who, otherwise, would have been roaming the streets, looking for employment. Baluster production does not require sophisticated technology: only simple tools and locally-available materials are employed (i.e. design moulds, twine, trowels, iron rods, cement, sand, and water). Though taught routinely as part of the Sculpture curriculum of Art Schools, it is a craft that can be easily learned by any artisan; in fact, most practitioners of this trade pick up casting skills as roadside apprentices - not through formal education. Correspondingly, it does not require a large capital-base for take-off. Micro-credit facilities exist locally for such small- and medium-scale enterprises. The balusters are reasonably affordable, with prices ranging between $\$ 1.50$ and $\$ 2.50$ per baluster, depending on the height and design complexity.

A social dimension to the issue of sustainability in the production of balusters (apart from the economic considerations above) is its comparative safety: one other popular enterprise engaged in by the nation's youth (either as a permanent



Figures 21: Baluster-type in figure 20, used in a balustrade to an external staircase. 


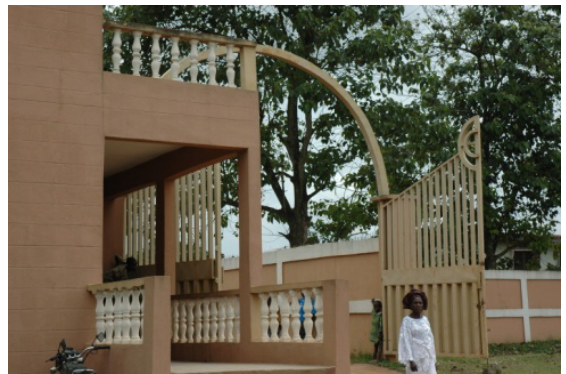

Figures 22: Baluster-type balustrades at Adesanoye civic centre, Ondo.

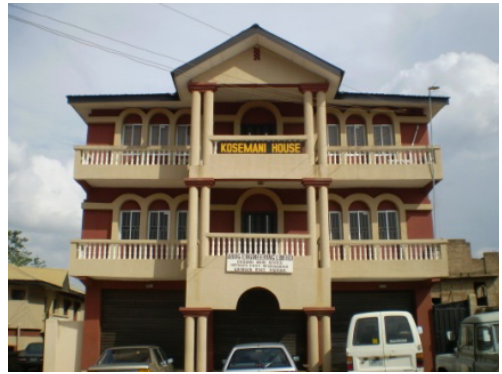

Figures 23: Mixed-use building: offices and shops. Osogbo.

vocation, or as a stop-gap pending the opportunity of admission to an institution of higher learning) is motor-bike riding as a means of public transportation. Locally termed okada it is an occupation fraught with uncertainty and high risks.

Still on social issues, those property-owners who, in the past, chose to integrate the inscription of their religious beliefs or personal motto in the articulation of their balustrade (i.e. people who favoured a customized design as in fig. 8), they saw it as a means of making a social statement [12] - that is, a tool for projecting a particular social image; contemporarily, because the use of the baluster-type balustrade moves a project beyond the realm of the routine (or purely utilitarian), if the initial capital outlay becomes somewhat enlarged (in the bid to accommodate such concrete balustrades), the prestige conferred is seen as making the additional expense worthwhile.

Though in Nigeria, the commonest context of the use of the baluster-type balustrade is residential architecture, it is not limited to this alone. Other typologies that have embraced its use - probably similar to what also obtains in other parts of the world - include commercial, educational and corporate. Figs. 22 and 23 show two such contexts of the new-look concrete balustrade.

\subsection{Cultural benefits of the balustrade}

For many years now on the architectural scene in Nigeria, there has been much talk about evolving a Nigerian architectural identity. Unfortunately, up till now, individual architects are mostly busy "doing their own thing". However, this notwithstanding, there appears to be a subtle, progressive characterization of contemporary Nigerian architecture - residential, institutional and recreational by a copious use of the concrete balustrade. Could a spontaneous integration of sculpted balusters and handrails - a focalizing of balustrade design - be the direction in which Nigerian architects must look to evolve a characteristic Nigerian architectural expression? Only time will tell.

The last statement notwithstanding, with a detailed study of Nigerian vernacular architecture, along the lines of ethno-cultural location - particularly the older expressions of the style - it is possible to relate a particular people's artistic concepts to the motifs used. This is particularly true of the Bini (or Edo) 
of mid-western Nigeria (who have a rich and ancient art culture with strong, characteristic defining expressions) and the northern parts of the country where the islamization of the region has strongly conditioned every facet of the people's lives, and their art expressions have been reduced to abstract forms, chiefly characterised by the arabesque.

\subsection{Challenges of balustrade production}

Generally, the cost of building a house in Nigeria is enormous - given the fact that the prices of building materials are invariably on the increase, with people's economic capacity far from being commensurately mobile. Hence, the obvious challenge affecting the design and production of the concrete balustrade is that of high construction costs (both in terms of material and labour); if general building costs were much lower, the baluster-maker's clientele would be inversely enlarged. With the wage profile of the average Nigerian pitiably low, people try to avoid anything that will unnecessarily add to the cost of house-building. Though a concrete balustrade provides additional aesthetics to the facade of a building, it is still slightly more expensive than routine masonry-work, and only those who appreciate beauty and can accommodate the additional cost, will consider going the extra mile. In addition, the fact that the prices of the production materials are not stable (correspondingly making selling prices unpredictable), could discourage investment in the business. All this notwithstanding, even with unpretentious (not professionally-produced) residences, the concrete balustrade is still proving popular, and an index for portraying "enlightened" tastes and general progressiveness.

One factor that could have greatly militated against the folk production of the balustrade is that craftsmen who had the knowledge of folk designs and indigenous construction methods are on the way out; in fact, the authors had their work cut out locating one! Indigenous knowledge vis-à-vis the overall practice has therefore, become threatened by extinction (as it has not been passed down, or properly documented for others to learn from). This situation is responsible for the failure to re-popularize the indigenous practice, vis-à-vis the slab-type concrete balustrade. The good news, however, is that in many Art Schools (i.e. in colleges of education, polytechnics and universities), modern techniques of producing balusters and other architectural accessories are being taught in the sculpture department; also, as earlier-stated, the contemporary techniques are easy to learn, informally. As is to be expected, however, the design vocabulary and overall formal expressions of these formally-trained practitioners (as well as the roadside apprentices) are pronouncedly different from those of artisans of days gone by.

\section{Sustainability and tourism}

All over the world, architecture-based tourism is common-place. Even if the primary attraction for holidaying in a foreign land is not to view its architectural monuments (but to savour its other cultural and physical endowments), it is an 
incontrovertible fact that the built environment will always make an impression on the tourist - consciously or unconsciously. Entrenched patterns of environmental aggregation, formal articulation, elemental features, materials and techniques, constitute planning and architectural styles. As such, repeated themes and schemes in the builtscape confer territorial identity and, by association of phenomena, convey cultural correspondence to the tourist. While, contemporarily, it may be difficult to talk of there being a unique "Nigerian Style", it stands to reason that it is what is repeatedly portrayed as representative of how we want to express our built-form, that will be used to define it by the tourist. For now, all over our cities, the baluster-type balustrade is holding centre-stage.

For the tourist who is particularly keen on the local architecture, it should be interesting to follow the progression from colonial and Brazilian balustrades to the present revival. In addition, as stated earlier, it is quite possible, on an ethnic basis, to note culture-defining differences in the expressions of concretebalustrade designs. It is, however, rather sad that many of the buildings that should provide visual evidence of this transit, are either derelict or have totally disappeared, due to individual or corporate negligence. (In Ile-Ife, for instance, the unfortunate incidence of the Ife-Modakeke internecine wars has resulted in many Afro-Brazilian buildings displaying exquisite panel-type concrete balustrades being wantonly razed by fire e.g. figs. 7 and 10).

Doubtless, in the developed nations of the world, balusters are routinely produced in factories; as such, their production is no longer a "craft". However, in the same sense as a tourist would visit, say, Beamish Museum in (north-east England) and watch the "traditional" production of butter (which is turned out by the tonne in ultra-modern factories today) and also listen to music being ground out of a hurdy-gurdy (when even the disc-man is fast becoming dated), a Western tourist to Nigeria may well find the fact that he can watch concrete balusters being painstakingly manually-produced, quite an eye-opener and a worthwhile diversion.

\section{Conclusion}

Concrete balustrades in Nigeria are currently the offshoot of a stylistic revival. They appear in various forms and material options, depending on the designer's preference and creative ingenuity. In the light of the current wave of high popularity, their production is giving economic independence to many young people, and the production techniques have been institutionalized in formal curricula. Tourists interested in architectural history should find the present revival interesting and worth their while to probe.

For general sustainability, it is useful that Nigerian architects and builders locally contextualize, when writing specifications for designs; this implies patronage of indigenous knowledge, technology and materials, where feasible. Such an orientation will facilitate the creation of job opportunities for up-andcoming, enterprising Nigerians, and save the nation's hard-earned foreign reserves. 


\section{References}

[1] Frampton, K., Modern architecture, Thames and Hudson Ltd.: London, 2000.

[2] Seeley, H., Building technology, Macmillan Press Ltd.: London, pp. 146150, 1974

[3] Osasona, C. O. \& Hyland, A. D. C., Colonial Architecture in Ile-Ife, Nigeria, Bookbuilders, Editions Africa: Ibadan, pp. 64-66, 106-108, 2006.

[4] Tour of Old Lagos; online, enownow.com

[5] Hallen, B., Afro-Brazilian mosques in West Africa, MIMAR 29, pp. 16-23, 1988.

[6] Osasona, C. O. \& Hyland, A. D. C., Colonial Architecture in Ile-Ife, Nigeria, Bookbuilders, Editions Africa: Ibadan, pp. 11-29, 2006.

[7] Aradeon, S., A history of Nigerian architecture: the last 100 years, Nigeria Magazine, 150, pp. 1-8, 1984.

[8] Beier, H. U., Yoruba cement sculpture, Nigeria Magazine, 46, pp. 144-156, 1955.

[9] Brown, M., Point break. Houses, 16, pp. 46-49, 1998.

[10] Brown, M., Verandah lifestyle, Houses, 16, pp. 58-61, 1998.

[11] Shonfield, K., BDP's Bournemouth library, The Architects' Journal, 11 (217), pp. 30-35, 2003.

[12] Osasona, C. O., Symbolism in traditional African architectural decoration, The Nigerian Field, 55 (3 \& 4), pp. 99-107, 1990. 